\title{
Reflexiones en torno a la historia de las relaciones entre tojolabales, tseltales y chujes
}

\section{Reflections about the History of the Relationship Between the Tojolabal, the Tseltal, and the Chuj Peoples}

\author{
Fernando Guerrero Martínez \\ iD ORCID: https://orcid.org/0000-0003-4883-4218 \\ Universidad Nacional Autónoma de México \\ Centro de Investigaciones Multidisciplinarias sobre Chiapas y la Frontera Sur \\ fernandoguerrero@comunidad.unam.mx
}

Resumen:

El trabajo parte de la consideración de que el idioma tojol-ab'al es una lengua mixta, surgida a partir del contacto entre tseltal y chuj, según estudios lingüísticos recientes. Tomando en cuenta esto, se analiza la información disponible acerca de la historia de dichos pueblos mayas y sus relaciones, mediante la articulación de datos provenientes de documentos coloniales y su estudio desde la disciplina histórica, con aquellos derivados de investigaciones etnográficas. Se muestran las pruebas que permiten hablar de una región multilingüe en la que confluyeron diversos grupos en el siglo XVI, mientras que, desde la visión de los habitantes actuales, historia y mito se entrelazan para explicar movimientos poblacionales y vínculos entre comunidades a lo largo del tiempo. El análisis invita a considerar uno de los escenarios hipotéticos propuestos desde la lingüística para el tipo de contacto que pudo haberse dado entre tseltal y chuj.

Palabras clave: contacto lingüístico, lengua mezclada, mayas, narrativas, historia y mito.

\section{Abstract:}

This work stems from the consideration that the Tojolabal language is mixed: it comes from the contact between Tseltal and Chuj, according to recent linguistic studies. Taking this into consideration, we analyze the available information about the history of these Mayan peoples and their relationship through time. This is accomplished by articulating data from ethnographic research and colonial documents, seen from a historic point of view. Evidence suggests a multilingual region in which diverse groups met during the XVI century, while from the point of view of current inhabitants, history and myth are linked to explain the population movements and links throughout time. The analysis invites to consider one of the hypothetical scenarios proposed by linguists about the kind of contact that may have happened between the Tseltal and the Chuj.

Key words: linguistic contact, mixed language, Mayan, narrative, history and myth. 


\section{Introducción}

E n los últimos años se han publicado los resultados de un par de investigaciones en el campo de la lingüística que han contribuido de manera sobresaliente al estado del conocimiento del idioma tojol-ab'al y, a su vez, han abierto un panorama investigativo que está por vislumbrarse a cabalidad en los siguientes años, no solo al interior de los estudios sobre dicha lengua y la familia maya, sino en general con respecto a las lenguas mesoamericanas. Me refiero en especial al artículo de Danny Law (2017a) y a la tesis doctoral de José Gómez (2017). No obstante, las repercusiones teóricas que tienen los descubrimientos hechos desde el campo lingüístico permean en buena medida nuestra comprensión sobre la propia historia del pueblo tojol-ab'al antes y después de la conquista española, y nos hablan de las relaciones que dicho grupo maya ha entablado históricamente con pueblos vecinos a ellos. Se trata, pues, de la demostración de que se trata de una lengua que debe considerarse, de acuerdo con la terminología lingüística, como mezclada o mixta, producto del contacto entre las lenguas tseltal y chuj. Esta afirmación, además de traer consigo un replanteamiento acerca de la representación de su filiación genética dentro de la familia lingüística maya, comprende una serie de reflexiones trascendentales con relación a la historia de una amplia región que hoy es atravesada por los límites políticos entre dos países.

En ese orden de ideas, la pregunta que da cauce al presente trabajo es: ¿cómo podemos repensar la génesis e historia del pueblo tojol-ab'al de acuerdo con los recientes hallazgos lingüísticos y tomando en cuenta la importancia de sus vínculos con los pueblos vecinos? En correspondencia, el objetivo es reunir y analizar la información disponible acerca del contacto entre los pueblos mencionados, por medio de la revisión de datos provenientes de estudios de carácter histórico y etnológico que vinculan a los pueblos tojol-ab'al, tseltal y chuj, principalmente, pero considerando también a otros pueblos mayas de las tierras bajas. En particular, se busca analizar las evidencias existentes con respecto a los escenarios potenciales en los que se pudo haber desarrollado la lengua tojol-ab'al de acuerdo con la propuesta de Law (2017a). En otras palabras, mirar con nuevos lentes las principales aristas del problema, aún sin resolver, de la distribución de los tojolabales antes del contacto con los españoles y en los primeros siglos del periodo colonial, así como reflexionar, en consecuencia, acerca de las fronteras étnicas y lingüísticas en una región maya marcada por la diversidad. 
Para esto será necesario mencionar las principales conclusiones a las que han llegado los recientes estudios lingüísticos acerca del tojol-ab'al, y enfatizar aqueIlas que se refieren a la naturaleza mezclada de dicho idioma, así como a los fenómenos conocidos como contacto lingüístico, cambio de código, bilingüismo y lexicalización congruente. Esta síntesis configurará el terreno sobre el que se reunirán datos de diversa índole, provenientes primordialmente de estudios de carácter histórico, para revisar la situación de las lenguas involucradas en el pasado. Posteriormente, se llevarán a la mesa de discusión las informaciones que, desde la memoria y la narrativa de algunos de los pueblos en cuestión, hablan acerca de su propia historia, con el fin de establecer contrastes y convergencias.

\section{El tojol-ab'al: de su clasificación monofilética a la demostración de su naturaleza mixta}

A pesar de que no existe duda acerca de que el tojol-ab'al es una lengua que pertenece a la familia lingüística maya, su posición al interior de esta nunca ha sido totalmente consensuada entre los especialistas. Esto se debe a que algunos autores han considerado que se trata de un idioma que debe ser ubicado dentro de la rama tseltalana, a consecuencia de su cercanía con la lengua tseltal -propuesta sustentada principalmente por Robertson (1977:120)-, mientras que otros han sostenido que su posición correcta es en la rama q'anjob'alana, ya que muestra mayores similitudes con el chuj (Kaufman, 1976:103; Schumann, 1983b:168; Campbell y Kaufman, 1985:188-189). Desde los primeros intentos por hacer una clasificación interna de las lenguas mayas, la postura de los investigadores con respecto al lugar del tojol-ab'al ha sido variada. Por ejemplo, en el trabajo pionero de Stoll (1884:177) -quien todavía se refiere al tojol-ab'al con el nombre de chañabal, término usado comúnmente en los siglos XVII y XVIII, junto con el de chanabal- lo ubica en el grupo tseltal, junto con el chol, el tsotsil, el propio tseltal y el chontal. Más de medio siglo después, Kroeber (1939:114) lo coloca anejo al chuj, pero de manera cercana al grupo tseltal (tseltal y tsotsil) y al popti'; Halpern (1942) lo pone entre el chuj y el grupo formado por el chontal, el chol y el ch'orti'. Tomando en cuenta dichas propuestas, McQuown (1956:195) -seguido por Swadesh (1960:232)- decide juntar al tojol-ab'al con el tseltal y el tsotsil, en el grupo tseltalano, independiente del chuj. 
Fue Kaufman (1964) quien sugirió por primera vez que el tojol-ab'al y el chuj forman un subgrupo dentro de la familia maya, lo cual fue apoyado por Schumann (1970). Sin embargo, unos años después, Robertson (1977:107) sostuvo que «no hay datos que sugieran un periodo de desarrollo común para el chuj y el tojol-ab'al», y que el último presenta muchas características en común con el tseltal, la mayoría de ellas innovadoras. Eso lo llevó a concluir que «el subgrupo tojol-ab'al-chuj de Kaufman, por lo tanto, no es sostenible» (Robertson, 1977:120). A pesar de esto, la hipótesis de Kaufman ha tenido, hasta el momento, mayor aceptación entre los especialistas en términos de la cantidad de trabajos que hacen referencia a su postura, en comparación con la otra. ${ }^{1}$ De hecho, la propuesta que reúne al tojol-ab'al con el chuj aparece en una de las publicaciones más recientes e importantes acerca de las lenguas mayas, y es sustentada por Campbell (2017:44-45) y Kaufman (2017:66), aunque en el mismo volumen se encuentra un trabajo de Law (2017b:120-121) en el que se explica la naturaleza mixta del tojol-ab'al como un caso especial dentro de la familia maya, y que implica poner en tela de juicio cualquier intento por trazar una sola línea de ascendencia para el idioma -es decir, de origen monofilético-, como se ha hecho tradicionalmente al tratar la clasificación de las lenguas, lo cual también es mencionado por Gómez (2017).

La cuestión genealógica del tojol-ab'al dio un giro en la primera década del siglo XXI, pues Law (2009) abrió la puerta para considerar de otra manera la filiación de esta lengua. En su estudio sobre los préstamos lingüísticos a nivel de los pronombres en la familia maya, este autor encontraba sumamente problemática la clasificación del tojol-ab'al, y afirmaba que sus rasgos solo podrían provenir ya fuera del contacto masivo con la rama tseltalana, o bien con el chuj, aunque optaría por apoyar la hipótesis de Robertson (1977) en cuanto a la cercanía del tojol-ab'al con el grupo tseltal-tsotsil debido a que, solo con respecto a las marcas de persona, "es el argumento más simple», aclarando que no está totalmente convencido (Law, 2009:238). Apenas como una idea esbozada en una nota al pie, Law (2009:238, nota 23) se inclinaría a pensar que, según sus estudios preliminares:

1 Sin embargo, siguiendo a Law (2017a:44), de todas las referencias que mencionan la cuestión, únicamente cinco estudios, de tres autores, son los que abordan el tema aportando datos lingüísticos. Estos son los de John Robertson (1977 y 1992), Otto Schumann (1983a y 1983b) y Karen Dakin (1988). Faltaría agregar el artículo de Otto Schumann (1970) «La posición del tojolabal en la familia maya», en el que ofrece elementos léxicos y morfológicos para apoyar la propuesta de Kaufman con respecto a que el tojol-ab'al forma, junto con el chuj, un subgrupo al interior de la familia maya. 
La cantidad de influencia lingüística en esta situación parece notablemente similar a la reportada para varios "idiomas mixtos", como Ma'a y Media Lengua [...], aunque se necesitaría hacer mucha más investigación antes de poder aplicar con confianza una etiqueta tan fuerte al tojol-ab'al (Law, 2009:238, nota 23).

Sin duda, dicha perspectiva de estudio fue tomada en serio por el autor. Le llevó algunos años más desarrollar su propuesta sustentada en múltiples evidencias, la cual trataría de manera abundante en su tesis doctoral (Law, 2011: 269-330). En ese orden de ideas, el capítulo 6 de la disertación de Law (2011) -que se convertiría en un artículo publicado en 2017- marcaba un rumbo a seguir en cuanto al estudio del idioma tojol-ab'al. Gómez (2017) ensancharía ese camino con una obra en la que respaldaba la propuesta del autor estadounidense y ampliaba el nivel de la comparación a muchas más estructuras morfosintácticas y entradas léxicas. Demostró la pertinencia de colocarle al tojol-ab'al la etiqueta de 'lengua mixta'. Serán ambos trabajos la referencia utilizada en las siguientes líneas para explicar de manera breve la naturaleza mezclada de dicho idioma maya.

Para comenzar, es conveniente decir que no existe una definición única y consensuada de lo que significa una 'lengua mezclada' (Matras, 2009:288; Gómez, 2017:55), y el concepto ha ido transformándose al tiempo en que se conocen más detalles de las estructuras gramaticales de los idiomas involucrados, así como de las situaciones históricas y socioculturales particulares en las que han emergido. De forma interesante, el caso del tojol-ab'al manifiesta la complejidad de la conceptualización de este tipo de lenguas, debido principalmente al vínculo genético de los dos idiomas relacionados con él. De acuerdo con Matras (2009), el combinado que existe en una lengua mixta se distingue de otro tipo de amalgamas que son resultado de cambios inducidos por contacto, y que, como un subgrupo dentro del conjunto de lenguas en contacto:

Los idiomas mixtos se consideran mezclados en la medida en que su afiliación genética no puede atribuirse a un solo linaje en particular [...], mientras que la ausencia de procesos de simplificación como parte de su génesis los hace distintos de los pidgins y los criollos (Matras, 2009:288).

En esta definición, la idea de que una lengua mixta no puede provenir de idiomas genéticamente relacionados no se cumple en el caso del tojol-ab'al, como lo han señalado Law (2017a) y Gómez (2017), puesto que los idiomas que, desde ese perspectiva, le dieron origen -el tseltal y el chuj- son lenguas que sí están 
vinculadas filogenéticamente: comparten un hipotético ancestro común, que es el protomaya, con el que se conectan a partir de la rama tseltalana y q'anjob'alana, respectivamente.

Por otro lado, Auer (2014:294) ha propuesto recientemente que el común denominador en las definiciones de lenguas mixtas es, justamente, el hecho de su ascendencia dividida. Este autor menciona que hay dos grandes conjuntos de opiniones entre los especialistas sobre lo que es una lengua mezclada: uno que considera factible hacer una clara distinción entre dichos idiomas y aquellos 'no mezclados' -en los que solo existen préstamos lingüísticos ordinarios-, y el otro que argumenta que la diferencia no es diáfana y que se presenta, más bien, en forma de un continuo, postura que ha propagado y a la que se adscribe Auer (2014:294), y que es seguida por Gómez (2017:512) en referencia al tojol-ab'al. Esta postura maneja que los idiomas mezclados son simplemente casos raros que cuentan con préstamos lingüísticos masivos de una lengua a otra, y que la ascendencia dividida es gradual, pero inequitativa, ya que «una variedad mixta puede estar relacionada con dos lenguas ancestrales, pero en la mayoría de los casos, uno de estos idiomas será el dominante» (Auer, 2014:294). Sin embargo, la preminencia del tseltal o del chuj en el caso del tojol-ab'al no es clara, ya que ambos proporcionan elementos a toda la gramática y el léxico de la lengua en cuestión (Gómez, 2017:512).

La inexistencia de una descendencia unilineal transparente para el tojol-ab'al explica en buena medida las diferentes posturas adoptadas por los especialistas en cuanto a su filiación genética -ya sea que lo hermanen al tseltal, por un lado, o al chuj, por otro (Law, 2017a:41) -. Empero, el hecho de que las lenguas con las que mayormente se relaciona al tojol-ab'al pertenezcan también a la familia lingüística maya, como se dijo líneas arriba, implica ciertos obstáculos a la hora que se intenta identificar la fuente de algún rasgo lingüístico, ya que ambas poseen elementos en común que pueden venir del protomaya, aunque su procedencia de ramas diferentes - de la tseltalana uno, de la q'anjob'alana el otro-permite hacer distinciones (Gómez, 2017:42).

Los elementos del tojol-ab'al que son analizados desde una perspectiva comparativa por Law (2017a) tienen que ver con rasgos compartidos con el tseltal y el chuj en tres niveles diferentes: la fonología, las estructuras morfosintácticas -entre las que incluye las marcas de persona, la posición de las marcas del absolutivo - juego B, el plural, el sistema aspectual, los sufijos de categoría, el sistema de voz, las preposiciones, y la negación-, y el léxico -que analiza tomando en cuenta 
un vocabulario básico, y otro extendido de 1200 ítems-. Por su parte, Gómez (2017) amplificó la comparación del tojol-ab'al con el tseltal y el chuj a partir de tres cuestiones: una lista léxica ampliada a 1479 ítems, el cotejo de distintas categorías léxicas a través de su morfología y sintaxis -entre las que destacan los sustantivos, los adjetivos, los verbos, los clasificadores, las raíces posicionales y los verbos de movimiento, y un primer acercamiento a la comparación de ciertos rasgos sintácticos, todo lo cual le confiere al estudio del mencionado autor un nivel de profundidad sobresaliente.

La naturaleza mixta del tojol-ab'al se refleja en la mayoría de las características comparadas mencionadas con anterioridad. Es decir, que este idioma toma, tanto a nivel léxico como gramatical, elementos del tseltal y del chuj. En algunos casos, los exponentes del tojol-ab'al son compartidos solo con el tseltal, y no con el chuj, pero existe también la situación inversa. Otros rasgos del tojol-ab'al se comparten de manera más abundante con el tseltal, y en menor medida con el chuj, y viceversa. Algunos rasgos muestran una distribución equitativa en cuanto al número de elementos que el tojol-ab'al comparte con el tseltal y con el chuj. También existen innovaciones del tojol-ab'al que no son compartidas ni con el tseltal ni con el chuj, así como retenciones que el tojol-ab'al mantiene del protomaya, y que comparte con otras lenguas como el chol. En el cuadro 1 se muestran algunos ejemplos que ilustran las posibilidades que se acaban de describir, y que demuestran la naturaleza mixta del idioma.

Cuadro 1: Algunas características lingüísticas del tojol-ab'al y su tipo de correspondencia con las del tseltal y del chuj

\begin{tabular}{|c|c|c|}
\hline Tipo de correspondencia & Rasgo lingüístico & Referencia \\
\hline \multirow[t]{2}{*}{ Tojol-ab'al solo con tseltal } & $\begin{array}{l}\text { Marcas de los pronombres } \\
\text { de primera persona singular y } \\
\text { plural de los juegos } A \text { y B }\end{array}$ & Law (2017a:50) y Gómez (2017:74) \\
\hline & $\begin{array}{l}\text { Sufijos de derivación deposi- } \\
\text { tiva }\end{array}$ & Gómez (2017:346) \\
\hline \multirow[t]{2}{*}{ Tojol-ab'al solo con chuj } & $\begin{array}{l}\text { Sufijos de categoría y de cla- } \\
\text { ses de raíz }\end{array}$ & Law (2017a:58) \\
\hline & Sufijos de derivación estativa & Gómez (2017:291) \\
\hline \multirow{5}{*}{$\begin{array}{l}\text { Mayoría de elementos del } \\
\text { tseltal y minoría del chuj }\end{array}$} & Marcas de plural & Law (2017a:52) \\
\hline & Sistema aspectual & Law (2017a:53) \\
\hline & $\begin{array}{l}\text { Sufijos de derivación de ver- } \\
\text { bos transitivos e intransitivos }\end{array}$ & Gómez (2017:99) \\
\hline & $\begin{array}{l}\text { Sufijos de flexión y derivación } \\
\text { de adjetivos }\end{array}$ & Gómez (2017:111) \\
\hline & Sufijos pluriaccionales & Gómez (2017:330) \\
\hline \multirow{2}{*}{$\begin{array}{l}\text { Mayoría de elementos del } \\
\text { chuj y minoría del tseltal }\end{array}$} & Sistema de voz & Law (2017a:59) y Gómez (2017:142) \\
\hline & $\begin{array}{l}\text { Verbos intransitivos de movi- } \\
\text { miento }\end{array}$ & Gómez (2017:496) \\
\hline
\end{tabular}




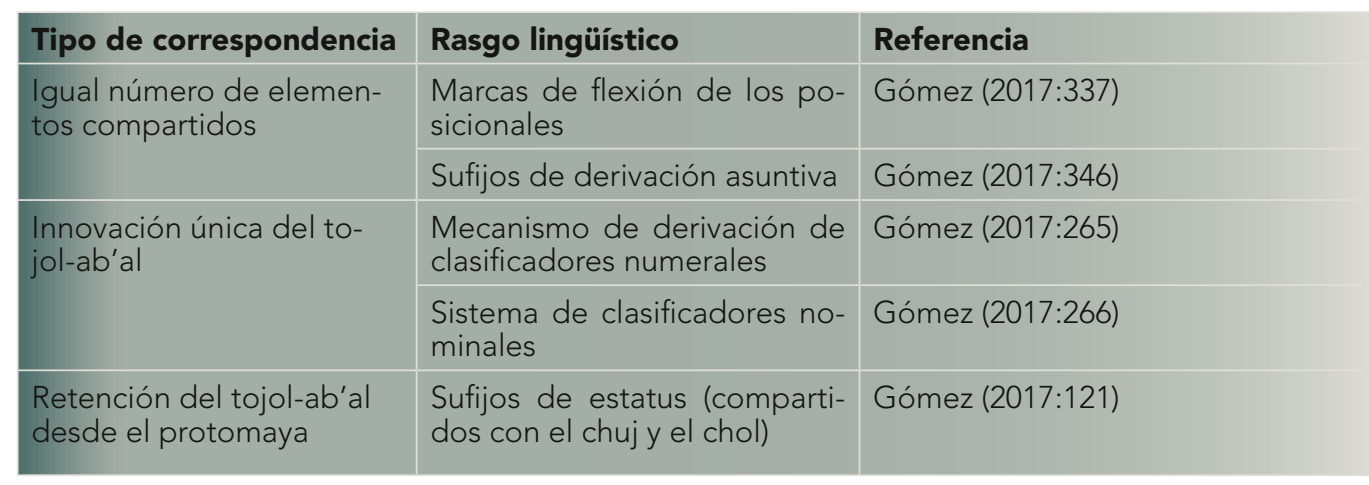

Fuente: elaboración propia con base en las referencias citadas.

En cuanto al léxico, tanto en la comparación hecha por Law (2017a) a partir de 1200 ítems, como en la de Gómez (2017) con 1479, los resultados indican que el tojol-ab'al comparte un mayor número de palabras con el tseltal que con el chuj, contrariamente a lo que se había obtenido con la comparación del vocabulario básico de estas tres lenguas (Schumann, 1983b; Law, 2017a). En el artículo de Law (2017a:64) se muestra que el tojol-ab'al comparte $41 \%$ de su vocabulario con el tseltal, $37 \%$ con el tsotsil, $37 \%$ con el cholti y solo $28 \%$ con el chuj. Por su parte, la tesis de Gómez (2017:38) ofrece otros números, ya que, de su muestra, el tojol-ab'al comparte con el tseltal $58 \%$ de su vocabulario, del cual $29 \%$ es también compartido con el chuj, y el otro $29 \%$ únicamente con el tseltal; además, el tojol-ab'al comparte con el chuj, y no con el tseltal, solo $13 \%$, mientras que $25 \%$ no es compartido ni por el tseltal ni por el chuj. De este último, dice el autor que falta investigar si dicho porcentaje corresponde a innovaciones o préstamos lingüísticos de idiomas cholanos (Gómez, 2017:39). Al respecto, ese 25\% del trabajo de Gómez podría estar en consonancia con los resultados que ofrece Law (2017a:64) con respecto al léxico compartido entre el tojol-ab'al y las lenguas cholanas, ya que, además del ya mencionado para el cholti, 33\% es compartido con el chol, $23 \%$ con el ch'orti' y $23 \%$ con el chontal de Tabasco. Estos resultados demuestran la importancia de la influencia de las lenguas cholanas en el tojol-ab'al, situación que ya había advertido Schumann (1983b:153), en especial con referencia al ch'orti'. No obstante, la similitud, citada líneas arriba, entre el tojol-ab'al y el cholti, ha sido interpretada como el «resultado de un contacto extenso con ese idioma de las tierras bajas» (Law, 2017a:69), idioma que se encuentra actualmente extinto, pero que se ha relacionado de manera cercana con los jeroglíficos del periodo Clásico maya (Houston et al., 2000:321). Sin embargo, la cuestión del vínculo del tojol-ab'al con los idiomas cholanos no ha sido profundizada ni aclarada. 
La mezcla que el tojol-ab'al tiene de rasgos del tseltal y del chuj ha sido hipotetizada por Law (2017a) a partir de diferentes escenarios históricos posibles. Uno de ellos sería que una comunidad de hablantes del tseltal se hubiera hecho bilingüe en chuj; otro escenario sería la situación inversa, y uno más, que «los hablantes de ambos idiomas pudieron haberse reubicado en una sola comunidad de origen mixto» (Law, 2017a:66). Estos tres escenarios son los que me interesa explorar a partir de las diferentes evidencias disponibles hasta el momento. No obstante, conviene recalcar que el estrecho vínculo entre el tojol-ab'al y el chuj:

Deja claro que estos idiomas tienen una extensa historia compartida. Ya sea que se trate de hablantes de una lengua tseltalana que interactúan con el chuj, o de hablantes de un idioma chujeano que se involucran en una intensa interacción con los hablantes del tseltal, es inevitable una conexión histórica con hablantes de chuj para explicar la forma del idioma (Law, 2017a:67).

Antes de abordar los aspectos históricos que ayuden a aterrizar uno de los escenarios como los mencionados arriba, es relevante delinear a grandes rasgos el tipo de contacto lingüístico propuesto por Law (2017a) con respecto al tojol-ab'al, ya que brinda pautas generales para revisar los datos históricos disponibles en dicha materia, y los elementos que son destacados en la creación de un idioma mezclado. Después de considerar algunas evidencias históricas y etnográficas, el citado autor menciona que una de las características fundamentales que debió estar presente en el origen mixto del tojol-ab'al tiene que ver con lo que se conoce en lingüística como 'cambio de código' (Law, 2017a:69-70), el cual puede definirse de manera sencilla como «la sucesión rápida de varios idiomas en un solo discurso» (Muysken, 2000: 1). Law (2017a) sugiere que, en el caso del tojol-ab'al, el patrón de cambio de código debió de corresponder con el propuesto y descrito por Muysken (2000:3) como 'lexicalización congruente', el cual se distingue de los otros dos patrones llamados 'inserción' y 'alternancia'. El patrón de inserción se da cuando se introducen ítems léxicos o constituyentes completos de una lengua en la estructura de otra; el patrón de alternancia, en cambio, se da justamente entre las estructuras de los idiomas involucrados en el cambio de código; mientras que el patrón de lexicalización congruente se distingue por incorporar material de diferentes inventarios léxicos en una estructura gramatical compartida (Muysken, 2000:3).

Este último es el que se propone para el tojol-ab'al, pues «es un patrón en el que los cambios de código son comunes en todos los puntos, dentro y entre 
las cláusulas, e incluso al interior de las palabras» (Law, 2017a:71). La ventaja de considerar que el patrón de lexicalización congruente -como parte del fenómeno lingüístico de cambio de código- se dio en algún momento de la génesis del tojol-ab'al es que involucra la mezcla gramatical y léxica de las 'lenguas madre' -tseltal y chuj-. Como dice Muysken (2000:127), a nivel teórico, «ambos idiomas contribuyen a la estructura gramatical de la oración, que en muchos casos es totalmente compartida por los idiomas involucrados. El vocabulario proviene de dos o más idiomas diferentes, pero también puede ser compartido». De acuerdo con Lipski (2009:3), el factor lingüístico que favorece la lexicalización congruente es justamente la similitud tipológica de los idiomas involucrados-aquí es donde toma importancia la similitud inherente de los idiomas madre, destacada por Law (2017a) y Gómez (2017), debida al vínculo filogenético-, a diferencia de los patrones de inserción y alternancia, en los que es necesaria una distancia tipológica entre las lenguas. Con relación a los factores extralingüísticos, Lipski (2009:3) señala que, en la lexicalización congruente, los dos idiomas tienen aproximadamente el mismo prestigio, y no hay una separación manifiesta de las lenguas. La relación de la lengua mezclada con sus idiomas de origen es un rasgo muy importante de las lenguas mixtas, tanto como el tipo de lazos que mantienen las lenguas madre entre sí. ${ }^{2}$ De esta manera, se podría pensar que el tojol-ab'al nació en un contexto de cambio de código generalizado, utilizado en comunidades bilingües en tseltal y chuj (Law, 2017a:43-44). Al respecto, conviene exponer que el bilingüismo comunitario es una de las características que ponderan Matras y Bakker (2003:1) para la definición de las lenguas mezcladas, y que es retomada por Gómez (2017:60) para el caso del tojol-ab'al.

Aunque existen otros elementos relevantes acerca de las lenguas mixtas, por ejemplo, la pérdida del contacto con las lenguas fuentes y otros factores sociales (Thomason, 2003), así como la identidad (Croft, 2003) y la dimensión lingüístico-histórica (Matras y Bakker, 2003), por ahora resulta adecuado revisar la información de carácter histórico que se tiene hasta el momento con respecto al pueblo tojol-ab'al, con el fin de pensar las propuestas generadas a partir de los estudios lingüísticos, en el marco del desarrollo histórico de los tojolabales y su vínculo con tseltales y chujes, tomando en cuenta la probable región de contacto entre los últimos.

\footnotetext{
2 Es oportuno decir que muchos de los aspectos y procesos que viven los idiomas mixtos son discutidos ampliamente en el volumen The Mixed Language Debate. Theoretical and Empirical Advances, editado por Yaron Matras y Peter Bakker (2003). Remitimos al lector interesado para ahondar en el tema.
} 


\section{Lenguas y pueblos en movimiento: historia de los tojolabales y sus vecinos}

Varios autores han coincidido en que la información disponible acerca de la historia del pueblo tojol-ab'al es, por decir lo menos, escasa y contradictoria (Ruz,1983a:24; Lenkersdorf, 1986:13; Álvarez et al., 1995:603; Law, 2017a:66). El hecho de que el nombre del pueblo -identificado más bien por la lengua, ${ }^{3}$ denominada chanabal- no aparezca en un documento colonial antes de 1686 ha generado que algunos especialistas tengan dudas acerca de la distribución del pueblo tojol-ab'al a principios del siglo XVI (Ruz, 1983a; Álvarez, 1993; Lowe y Álvarez, 2007). Por tal motivo, y después de un análisis minucioso de varios documentos coloniales, en conjunto con las interpretaciones lingüísticas de la época, Ruz (1983a:47) adelantó la hipótesis de que «quizá la explicación más plausible es que el grupo haya permanecido, en los inicios de la Colonia, en las zonas selváticas o montañosas cercanas, clasificados dentro de términos ambiguos tales como 'choles' o 'lacandones'», no sin descartar la posibilidad del «establecimiento original del grupo en un área cercana a la hoy ocupada por los chujes, de donde emigraron al hábitat actual» (Ruz, 1983a:47). Sin embargo, el trabajo de Lenkersdorf (1986) daría vuelta a dichas interpretaciones y, como el propio Ruz (1986:9) señalaría, «la inexactitud de la mayor parte de nuestras hipótesis es demostrada en forma contundente a lo largo del artículo». La contribución de la investigadora alemana al conocimiento de la historia tojol-ab'al se calificaría como «la más importante hasta hoy día sobre el tema» (Ruz, 1986:9), y sería defendida por la autora en varias publicaciones, ${ }^{4}$ así como retomada constantemente en otros trabajos que, con posterioridad, darían su visión sobre la historia de la región. ${ }^{5}$ La conclusión principal de Lenkersdorf (1986) es que los tojolabales se han distribuido en la región que actualmente habitan, desde, por lo menos, el siglo XVI, «hipótesis que implica que los términos coxoh, chanabal y tojolabal,

3 Leopoldo Valiñas (2010:135) analiza parte del problema respecto a la atribución de una cierta identidad a un determinado grupo social, a partir de la lengua que habla, y argumenta que «lo social y lo lingüístico son dos realidades decididamente diferentes y las razones para nombrarlas responden a estrategias muy (pero muy) distintas» (Valiñas, 2010:135). Al respecto, Lenkersdorf (2001:174) señala que, en Chiapas, a mediados del siglo XVI, los dominicos decidieron identificar a los pobladores con el mismo nombre que los idiomas que hablaban, de manera que «las lenguas comenzaron a servir para diferenciar a los indios en tzotziles, tzeltales, zoques y otros. Hasta nuestros días la identidad de los indios en los censos oficiales se ve todavía reducida a su lengua».

4 Véanse, por ejemplo, Lenkersdorf (1993; 1995; 2001).

5 Tales como los estudios de Ruz (1992b:41; 1999:29), Gómez y Ruz (1992), Viqueira (1997), Cruz y Robledo (2003), Castro (2005), Lowe y Álvarez (2007). 
que se han aplicado durante varios siglos a los habitantes de la zona, se refieren a la misma etnia» (Lenkersdorf, 1986:13), conjetura que, precisamente, acababa con la problemática descrita con anterioridad, pues:

Tiene la virtud de explicar la presencia del grupo tojolabal en Chiapas -se trataría sencillamente de los antiguos coxoh-, sin tener que postular la existencia de migraciones ocurridas en la segunda mitad del siglo XVII de las que no se ha podido encontrar mención alguna en los documentos de la época (Viqueira, 1997:37).

En su estudio, Lenkersdorf (1986) discute profunda y detalladamente los datos, citas e ideas de los autores que habían mostrado dudas con respecto a la presencia de los tojolabales en la región de Comitán en los albores de la época colonial, haciendo especial referencia al trabajo de Lyle Campbell y Brant Gardner (1978), con quienes se abre un debate interesante en torno al coxoh. ${ }^{6}$ El objetivo de la historiadora alemana era clarificar la situación de la lengua hablada en Comitán y otros lugares cercanos en el siglo XVI, «pues el idioma es un indicio que permite identificar a cuál etnia se adscribía la población» (Lenkersdorf, 1986:13).? El interés, en el presente artículo, es utilizar algunos de los datos señalados por Lenkersdorf, tanto en la mencionada obra como en su libro Repúblicas de indios (2001), para hablar de una región que estuvo caracterizada por la presencia de múltiples lenguas mayas a lo largo de muchos años. Para ello, es necesario dar un panorama general de la región a inicios del siglo XVI, comprendida en lo que los españoles de la época denominaron la provincia de Los Llanos.

La provincia de Chiapa, creada en 1528 y poseedora de una extensión aproximada de 240 km de diámetro (Lenkersdorf, 2001:157), contaba con seis grandes regiones, entre ellas la llamada de Los Llanos (véase figura 1), las cuales fueron constituidas supuestamente «ya sea en torno al manejo de una misma lengua, o bien alrededor de la integración al mismo sistema de producción e intercambio de bienes, o con base en la sumisión al mismo régimen político y militar» (De Vos, 1994:42). Era común considerar que dichos territorios correspondían con una

6 La controversia es un tanto extraña en el sentido de las publicaciones en las que se presenta, puesto que Lenkersdorf (1986) refuta las interpretaciones ofrecidas en una ponencia de Campbell y Gardner del año 1978 (citado en Lenkersdorf, 1986), mientras que en el multicitado capítulo de Campbell y Gardner (1988), la obra de Lenkersdorf que contradicen es un manuscrito albergado en La Castalia, Comitán, de 1978. Es decir, que los documentos publicados más conocidos de dichos autores no se citan entre sí.

7 Debido a que no es posible reproducir aquí los diversos puntos que componen la cuestión, es fundamental que el lector consulte las obras señaladas de Lenkersdorf (1986) y de Campbell y Gardner (1988). 
configuración espacial presente desde antes de la llegada de los españoles, es decir, que existieron seis provincias prehispánicas análogas a las coloniales (De Vos, 1994).

Figura 1. Ubicación aproximada de las provincias coloniales de Chiapas

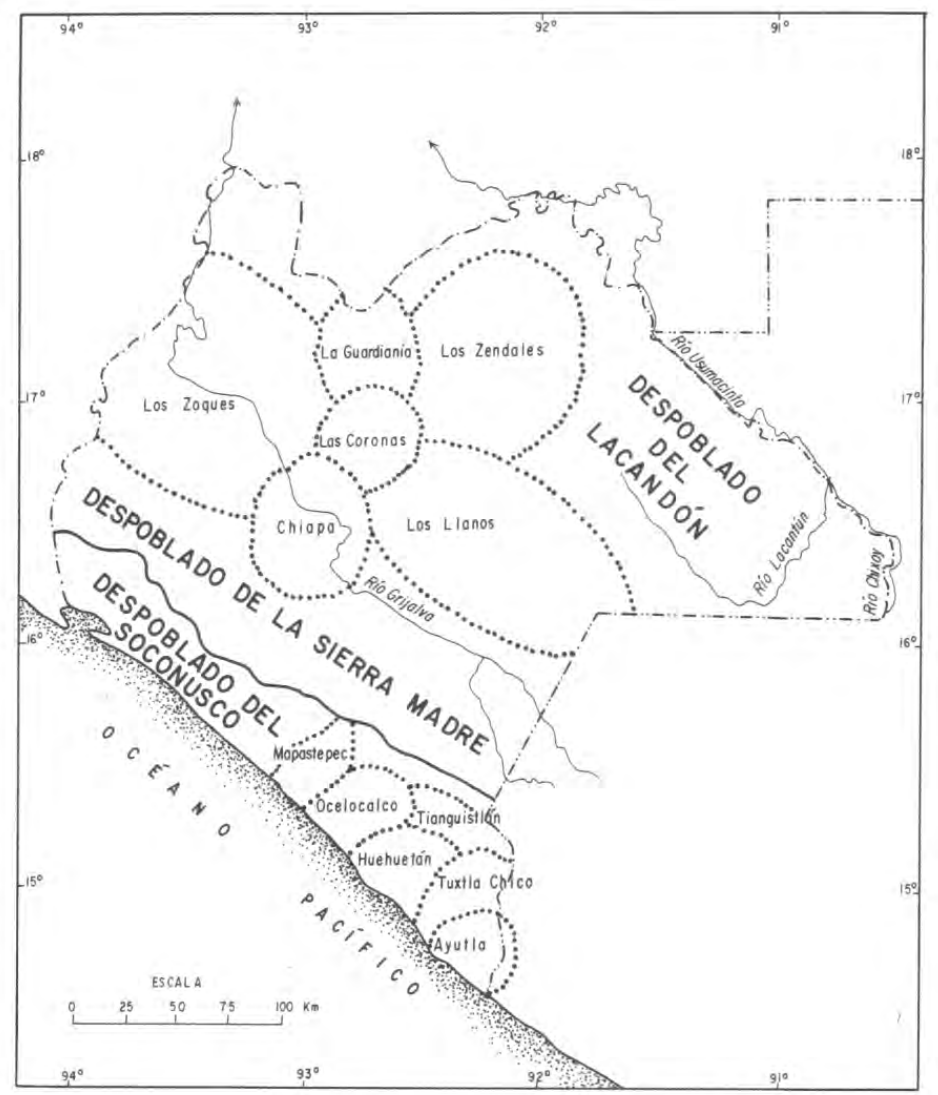

-..- Límite del actual estado de Chiapa

Límite natural entre

Chiapa y Soconusco

Fuente: Tomado de Jan de Vos (1994:58).

Sin embargo, Gudrun Lenkersdorf (2001), al profundizar en el estudio de la organización político-administrativa de los pueblos mayas en el siglo XVI, evidenció que tanto la provincia de Los Llanos, como las otras, «no correspondían a provincias prehispánicas que los europeos hubieses encontrado, como solían interpretarse» (Lenkersdorf, 2001:175). La provincia de Los Llanos era, en palabras de Ruz (1992b:45), un 'mosaico étnico' conformado por tojolabales, tseltales, coxohes, 
tsotsiles y cabiles, además de colindar con los pueblos mochó, lacandón, chuj, q'anjob'al, mam y popti'. Por su parte, Lenkersdorf (2001) afirma sobre dicha provincia que:

Correspondía a la cuenca del Río Grande y fue una típica creación colonial, contraria a los principios de los antiguos juyub tak'aj o altépetl cuyos distritos corrían en forma perpendicular por el valle. Así, la nueva demarcación contenía segmentos de los territorios de diferentes naciones antiguas y por ello aglomeraba poblaciones de lenguas diferentes (Lenkersdorf, 2001:175).

Es justamente esta diversidad la que me interesa resaltar, pues es el escenario clave para entender que, probablemente, los habitantes de muchos de los pueblos asentados en la provincia se podían comunicar con otros no solo en su lengua materna, sino en la de los vecinos. Esta afirmación se basa en las consideraciones generales que Leopoldo Valiñas aduce respecto a la historia lingüística mesoamericana; ese mismo autor señala la presencia de una complejidad de situaciones lingüísticas diversas a lo largo del tiempo, de manera que «las evidencias lingüísticas nos permiten suponer la existencia de diferentes situaciones multilingües y la coexistencia de relaciones sociales (y lingüísticas) asimétricas con las simétricas» (Valiñas 2010:146).

El área de la provincia de Los Llanos en la que centro mi atención abarca los pueblos de Comitán -centro político de la mencionada provincia colonial (Ruz, 1992b:41)-, Zapaluta -que hoy en día corresponde con La Trinitaria-, Copanaguastla -uno de los asentamientos más importantes de la región, desolado por las epidemias y abandonado en el siglo XVII-, los antiguos Pantla y Atahuistlán -ubicados en la zona actual de Las Margaritas, en pleno territorio tojolabal-, así como Coapa -uno de los pueblos coxoh-y Tepancoapa -adyacente a las lagunas de Montebello-, entre los más relevantes, sin olvidar la colindancia de esta región con las tierras de San Mateo Ixtatán -centro poblacional chuj ubicado ya en la sierra de los Cuchumatanes-, hacia el sur, y con la Selva Lacandona hacia el oriente, en la que se mencionará el asentamiento de Pochutla (véase figura 2). 
Figura 2. Lugares que se mencionan en este texto

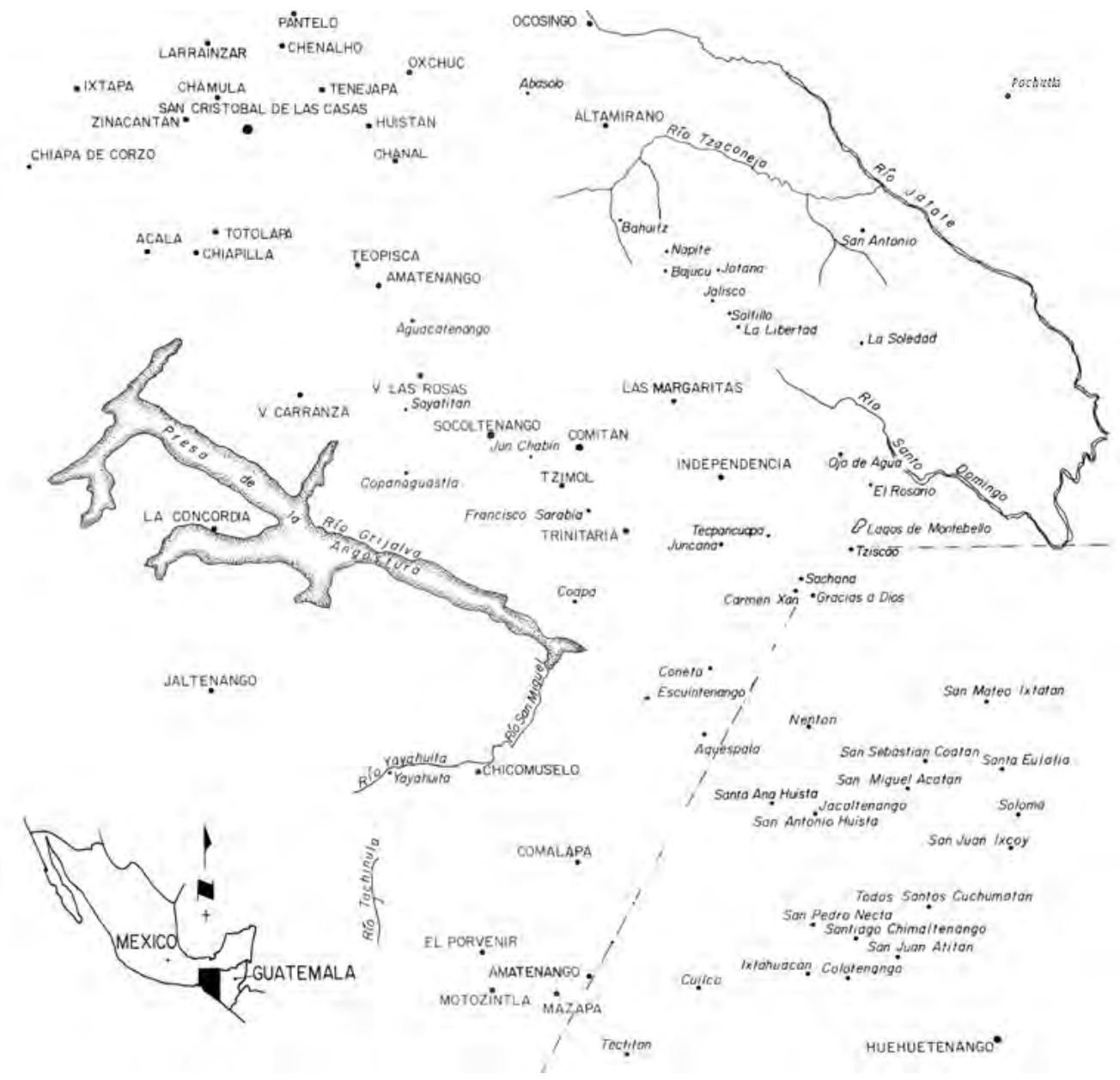

Fuente: Modificado de Campbell (1988: mapa 2).

Un hecho relevante es que en 1540, un lustro antes de que llegaran los dominicos a la región y comenzaran las congregaciones de los pueblos, se tiene noticia de que el adelantado Francisco de Montejo, a su paso por las tierras mencionadas, señala los pueblos más importantes de la alcaldía mayor de Chiapas: «yo visité los pueblos más principales de esta provincia que son en la provincia de Chiapa e Canacantlan e Teopuso e Comytan e Ataoztlan que son los pueblos más principales de esta provincia» (citado en Lenkersdorf, 2001:39-40, nota 174). No es difícil discernir, como lo sugiere Viqueira (1997:110, nota 16), que se trata de los pueblos de Zinacantán, Teopisca, Comitán y Atahuistán o Atahuistlán. Las lenguas habladas en los primeros dos lugares que menciona Montejo no resultan muy problemáticas de establecer, pues seguramente eran la tsotsil y 
la tseltal, respectivamente; sin embargo, para Comitán y Atahuistán la cuestión no es nada trivial, ya que, incluso, la obra de Lenkersdorf (1986) estuvo dedicada a atender el asunto, puesto que los autores que habían tocado el tema de la lengua hablada en Comitán se contradecían. La conclusión a la que llega la autora sobre el particular es que no existen argumentos sólidos y contundentes acerca de que se hubiera hablado tseltal en Comitán en el siglo XVI (Lenkersdorf, 1986:25), tesis opuesta a las sugerencias de Calnek (1970) -a quien la mayoría de los autores posteriores citan, por ejemplo, Ruz (1983a)-, y que contradice totalmente los postulados de Campbell y Gardner (1988) al respecto. Entre los datos más destacados que revisa la historiadora alemana está el idioma reflejado en el llamado Libro de Bautizos de Copanaguastla-Comitán, escrito de 1557 a 1583, que comenzó a redactarse en el pueblo tseltal de Copanaguastla, y que probablemente pasó a Comitán en 1576 (Lenkersdorf, 1986:18). La autora, después de examinar el documento, muestra cómo ciertas partes -en específico los términos de parentesco para 'hijo' o 'hija', y los nombres calendáricos- están escritas en tseltal, pero otras lo están más bien en tojol-ab'al (Lenkersdorf, 1986:21).

Regresando a la mención de Montejo acerca de que el pueblo llamado Atahuistán era uno de los principales en el siglo XVI, conviene decir que dicho asentamiento se encontraba a «seis leguas al noreste de Zapaluta y tres o cuatro al este de Comitán» (Lenkersdorf, 1986: 39-40). Con el desarrollo de una serie de investigaciones arqueológicas en la región, durante varios años, se ha podido demostrar que el antiguo Atahuistán corresponde con el sitio arqueológico denominado Cimientos de Las Margaritas, ubicado a poco más de un kilómetro al sureste de la cabecera municipal (Álvarez et al., 1995:604; Lowe y Álvarez, 2007:323). De acuerdo con Lowe et al. (2011:119), «el asentamiento ocupaba cinco islas ubicadas al interior de una ciénaga o laguna, conocida como Zacualpa, que fue drenada en épocas recientes con el fin de aprovechar el fértil fondo lacustre para el cultivo de caña de azúcar y maíz». Atahuistlán y Pantla fueron los sitios prehispánicos más importantes en la región de Las Margaritas durante el periodo Posclásico Tardío, de manera que «la topografía, en conjunto con los hallazgos arqueológicos provenientes de estos dos sitios, sugieren que estos son los pueblos mencionados en las fuentes del siglo XVI, y que en el momento de la conquista española se encontraban en su apogeo» (Lowe y Álvarez, 2007:323). En cuanto al antiguo Pantla, Lenkersdorf (1986:71) nos dice que su ubicación es «entre las actuales colonias tojolabales de Veracruz y de La Libertad, al norte de la cabecera municipal de Las Margaritas. La zona es asiento de un importante 
sitio arqueológico [...] Los habitantes de Veracruz le llaman najlem». Ambos sitios se han considerado, siguiendo a Lenkersdorf (1986), como el hogar de hablantes de tojol-ab'al en los albores del periodo colonial (Viqueira, 1997; Gómez, 2014).

Ahora bien, una situación notable acerca de estos dos asentamientos, trastocados irremediablemente en la primera mitad del siglo XVI con la llegada de los españoles, es que sufrieron pronto las congregaciones que impulsaron los dominicos, como se dijo antes, en una región que hacía frontera con las tierras no conquistadas por los españoles, dominadas por los llamados «indios infieles», los pochutlas y lacandones. Tales circunstancias facilitaron el desarrollo de constantes arremetidas de los no conquistados contra dichas poblaciones, recién los españoles las habían sometido (De Vos, 1988). En ese sentido, Lenkersdorf (1986:72), a través del examen de varias probanzas de méritos de algunos conquistadores y sus hijos, sugiere que tanto Pantla como Ataguistlán «fueron abandonados a causa de los ataques de los lacandones», y sitúa la defensa del primer lugar alrededor del año 1545. El difícil escenario de estos asentamientos como puerta de entrada a territorio insumiso proveyó de razones suficientes para que sus pobladores fueran reubicados por los religiosos en diferentes pueblos. Juan Pedro Viqueira (1997), basándose en las obras de Ruz (1983a) y de Lenkersdorf (1986), resume el asunto de la siguiente manera:

La política de congregación llevada a cabo por los dominicos en el siglo XVI alteró profundamente la distribución de la población en la región y llevó a hablantes de tzeltal y de tojolabal a convivir en las mismas repúblicas de indios. Los asentamientos tojolabales más próximos a la selva -que padecían de constantes ataques por parte de los indómitos lacandones- fueron abandonados y sus habitantes trasladados a otras partes más cercanas al Valle del Río Grande. Así, los pobladores de Tecpancoapa pasaron a formar una parcialidad del pueblo de Coapa, y los de Atahuistán una en Zapaluta. En los últimos años del siglo XVI, los destinos de los moradores de Pantla se separaron: unos fueron congregados en Comitán, mientras que otros fueron incorporados a Socoltenango. Por otra parte, los españoles Ilevaron a los tzeltales de Copaltenango asentamiento que se encontraba cerca de Teopisca- a poblar Zapaluta. De esta forma al principiar el siglo XVII sólo quedaban en la región dos pueblos, Comitán y Zapaluta, habitados ambos por tzeltales y tojolabales (Viqueira, 1997:125).

Respecto de Zapaluta, Lenkersdorf (1986) señala que la parcialidad proveniente del pueblo de Copaltenango -que estaba sujeto a Teopisca en 1528-, albergaba a hablantes de tseltal, y la misma autora obtuvo en Lomantán la noticia 
de que, según sus habitantes tojolabales, los pobladores de Zapaluta llegaron desde Chanal y de ahí se dispersaron. Es interesante que ya para el año de 1613 un título de encomienda tiene el registro de que Copaltenango estaba incorporado en el pueblo de Atahuistlán, "y aquél puede ser el origen del 'Calpul de los Cendales', mencionado en 1681 junto a Zapaluta» (Lenkersdorf, 1986: 39), evidencia que apoya el hecho de que Zapaluta estuvo conformado por hablantes de tseltal y de coxoh/tojol-ab'al desde el siglo XVI.

El caso del pueblo de Coapa resulta también interesante, pues, como se anotó arriba, ha sido considerado como un lugar donde se hablaba coxoh, y tenía una ubicación estratégica sobre el camino real a Guatemala, por lo que en el siglo XVI «fue, en un primer momento, el pueblo más grande y activo del área» (Viqueira, 1997:117), además de que recibió a pobladores del antiguo Tecpancoapa, ubicado este último cerca del sitio arqueológico de Chinkultic, a un paso de la región de los actuales lagos de Montebello (Viqueira, 1997). Sobre la información que disponemos acerca de Tecpancoapa, conviene citar una nota de Lenkersdorf (2001):

El territorio de los chujes se extendía desde los altos Cuchumatanes hasta los lagos cercanos a Tecpancoapa (hoy llamados lagos de Montebello). Los habitantes de este poblado fueron reubicados e incorporados a Coapa a mediados del siglo XVI. El capitán Juan Morales de Villavicencio, quien dirigió la expedición contra los lacandones en 1586 y luego se apropió de las tierras de Tecpancoapa, fue acusado por los "ixtatanes" (chujes) de no respetar sus mojones (Lenkersdorf, 2001:144, nota 16).

Este sugestivo dato trae consigo una problemática considerable, pues, por un lado, no coincide con la opinión de Ruz (1992b:117) acerca de que los tres grandes asentamientos de la región, Tecpancoapa, Atahuistlán y Pantla, eran «casi seguramente de origen tojolabal», y por otro lado, Tecpancoapa y lugares circunvecinos -como Gracias a Dios, Sacchana, Juncana, Zapaluta, entre otros- han sido reconocidos como de habla tseltal por algunos autores desde comienzos del siglo XX, como afirmó Eduard Seler (citado en Lenkersdorf, 1986:26). Campbell (1987) también registró la lengua tseltal en esta región, y decidió considerarla como una zona dialectal más de ese idioma, que denominó como tseltal del sureste; y después, junto con Gardner, dicho autor identificaría al coxoh colonial con este dialecto del tseltal (Campbell y Gardner, 1988:318). Sin embargo, el apunte de Gudrun Lenkersdorf (2001) basado en el reclamo de los chujes por las tierras de Tecpancoapa, tiene eco en un mapa publicado por la misma autora 
en su obra de 1986, elaborado como parte de un expediente sobre la asignación de tierras al común del pueblo de Comitán, en el que se muestran las tierras de Zapaluta en 1780, basadas en Títulos de 1599, y en donde es posible observar una anotación que dice «San Joseph, tierras de Zapaluta compradas a los indios de Ystatan» (Lenkersdorf, 1986). ${ }^{8}$ Esto corroboraría que, por lo menos en el siglo XVI, la zona de Tecpancoapa era de los chujes. Cabe mencionar que en los documentos coloniales es común encontrar las referencias hacia los chujes como 'ixtatanes' o 'istatanes', en concordancia con su asiento principal, San Mateo Ixtatán, reconocido por sus salinas. No obstante, Lenkersdorf (2001:177, nota 137) arguye que el término 'chujes' surgió en realidad como un apodo, caso similar al de los 'quelenes', aunque no aclara el origen del primero.

Dos cuestiones más quedan por tratar antes de abordar las visiones de los chujes y zapalutas sobre su propia historia, a partir de datos etnográficos contemporáneos. Una es que, como lo han notado Schumann (1983b), Gómez (2014) y Pérez (2019), muchos de los nombres de lugares de la región de Comitán y La Trinitaria provienen de la lengua chuj. El caso más notable es el de los topónimos que terminan con la palabra 'najab', que viene del chuj nhajab' 'laguna' (Academia de las Lenguas Mayas de Guatemala, 2003:70; Hopkins, 2012:216), como es el caso de lugares como Uninajab, Yocnajab y Jusnajab, por ejemplo. A diferencia del chuj, el tojol-ab'al emplea pampa ja' o paman para ese referente (Lenkersdorf, 2010:466); y en tseltal, por su parte, se usa pampam ha' o pamal ha' (Polian, 2017:483). Otros topónimos interesantes son los que tienen que ver con nombres calendáricos, como el sitio arqueológico de Jun Chavín en Comitán, que seguramente proviene del vocablo chuj jun, que es el número uno, y chab'in es la palabra para el mono araña (ALMG, 2003:22; Hopkins, 2012:48), de la especie Ateles geoffroyi. En tojol-ab'al, este primate es nombrado machin (Lenkersdorf, 2010:538)9 o ma'ax (Schumann, 1983a:362), mientras que en tseltal se dice max (Polian, 2017:425). Ruth Piedrasanta (2009:50) registra los nombres de los veinte días, Horas o K'u akwal entre los chujes contemporáneos, entre los que se encuentra Chab'in.

También hay una serie de designaciones de lugares que provienen de nombres calendáricos que tienen que ver con el día 'estrella', como el conocido Balun

\footnotetext{
8 El mapa proviene de un expediente del Archivo General de Centro América, que se inicia en 1743, citado en Lenkersdorf (1986:67, nota 351) como: AGCA, Chiapas, A 1.45.6, leg. 292, exp. 2027 (1743). Ruz (1992b:121, mapa 5) también reproduce esta referencia.

9 Otto Schumann (1983a: 362) dice sobre este nombre que «cabe hacer notar lo interesante del término machin, para chango o mono araña, ya que éste corresponde al nahua del golfo».
} 
Canan 'nueve-estrella', para designar a Comitán, que ha sido considerado siempre como un nombre tseltal, aunque 'estrella' en tseltal es ek' (Polian, 2017:241). En tojol-ab'al, 'estrella' se dice k'anal (Lenkersdorf, 2010:333), al igual que en chuj (ALMG, 2003:52; Hopkins, 2012:145), por lo que se podría pensar que el nombre más bien proviene de alguna de estas lenguas. Piedrasanta (2009:50) lo registra como k'ana en el calendario chuj, y Hopkins (2012:147) como k'ana'. A esta categoría de topónimos de origen calendárico corresponden los nombres de Juncana (Jun-k'ana), '1-estrella', asentado entre La Trinitaria y la región de los lagos de Montebello; así como Uaxacana (waxak-k'ana), 'ocho-estrella', ubicado en el municipio de Nentón, Guatemala, «cerca de Quen Santo, por donde pasaban los tojolabales en su romería anual a San Mateo Ixtatán» (Lenkersdorf, 1986:29, nota 110). Esto lleva a la historiadora alemana a decir que «este tipo de nombres se usaba solo en una región específica del sureste de Chiapas con extensión a Guatemala» (Lenkersdorf, 1986:30).

Volviendo al nombre calendárico de Comitán, resulta significativo que en el mentado Libro de bautizos de Copanaguastla-Comitán, del siglo XVI, el término 'Baluncanan' aparece no solo como posible nombre del pueblo, sino como apeIlido, cuestión de suma relevancia que apoya la hipótesis de Lenkersdorf (1986:70) acerca del significado de la palabra 'chanabal' no como 'cuatro lenguas' -como muchos autores habían propuesto-, sino como 'cuatro-señor'. La autora argumenta que "Chanaval fue un nombre calendárico, una variante de chanaghval (cuatro Señor); se perdió el sonido j ante una consonante, igualmente difícil de discernir para el oído no acostumbrado. Proponemos pues la evolución: chanaghval [chanajwal] $\rightarrow$ chanaval $\rightarrow$ chanabal» (Lenkersdorf, 1986:77). Este nombre aparece en 1558 como apellido de un padrino principal de bautizo del pueblo de Pantla, y constituye uno de los ejemplos en los que se utilizó el nombre de una persona para referir, al mismo tiempo, a un lugar, como muestra Lenkersdorf (1986:30) con Juan de Solís, quien era alcalde de Comitán en 1580, y que proporcionó el nombre a una de las dos parcialidades de dicho pueblo - llamada justamente 'Juan de Solís'-, junto con la de 'Gómez de Villafuerte', que proviene del nombre del encomendero. La autora se apoyó en la información que reportó Jan de Vos para 1700 respecto a los itzaes, en la que dice que «a veces la comunidad se confunde, no sólo con un clan más importante sino hasta con su jefe de éste. $Y$ en un caso se identifica toda la provincia con el nombre de una parcialidad, respectivamente del jefe de ella» (De Vos, 1980:416, citado en Lenkersdorf, 1986:30, nota 117). Es muy interesante que el mismo nombre calendárico de cuatro-señor, 
Chan Aghoal, aparece como el nombre del cacique que gobernaba el pueblo de Pochutla en 1564 (De Vos, 1988:56). Este lugar, asentamiento de los Ilamados pochutlas, que al igual que los lacandones se revelaron por mucho tiempo contra el dominio español, se edificó en plena selva sobre una isla en medio de una laguna, que fue identificada por Jan de Vos (1988:56) como la laguna de Ocotal Grande. No se conoce con exactitud qué lengua hablaban los pochutlas, pues muchos autores han opinado que era el chol debido a su ubicación, mientras que otros, incluyendo De Vos (1988:56), se inclinan a pensar que fue el tseltal, debido a que, además del nombre del cacique mencionado:

Pochutla formaba en 1537 una sola provincia con Ocosingo y Tuni, dos pueblos de habla tzeltal. El hecho de que Fray Pedro Lorenzo redujo en 1564 a los Pochutlas al pueblo de Ocosingo es otro indicio más de que ellos hayan hablado un dialecto tzeltal [...] De todos modos, los pochutlas no eran lacandones, como lo quieren afirmar algunos de esos autores. Eran vecinos de éstos, no sus primos hermanos (De Vos, 1988:56).

De todos estos datos resalta que Pochutla, al igual que Pantla, se construyó en medio de una laguna, por lo que se puede decir que, a grandes rasgos, ambos asentamientos compartían el mismo patrón, en el que destacan las construcciones en las cimas de cerros y en cuerpos de agua para un mejor control y defensa del territorio, hecho típico del Posclásico tardío en esa región (Palka y Lozada, 2018), además de compartir el mismo nombre calendárico de sus respectivos principales -chan-ajwal, 'cuatro-señor'-. El hecho de nombrar de igual manera al señor principal de un lugar, como al mismo pueblo o sitio, le hizo reflexionar a Lenkersdorf lo siguiente:

Parece que aquí encontramos dos costumbres: una, quizá observada desde la época prehispánica y reforzada por la costumbre de los españoles, que era que los pueblos importantes en esta región llevaban el nombre de su jefe o linaje principal; la otra, que estos principales fuesen los padrinos predilectos en los bautizos o los testigos más frecuentes en los matrimonios. Según esto, entre los padrinos de los primeros años pudiéramos encontrar a los antiguos jefes de los pueblos con los respectivos nombres calendáricos de ambos (Lenkersdorf, 1986:30-31).

La relevancia de estos datos radica en que pueden ser considerados pistas trascendentales que explicarían por qué el tojol-ab'al tiene una fuerte influencia de las lenguas cholanas, en particular del cholti y el chol, como se dijo en 
el apartado anterior, ya sea mediante un contacto directo con estas lenguas, considerando su vecindad y cercanía -recordando las descripciones de Pantla y Atahuistán como 'fronteras' con los pueblos de la Selva Lacandona-, o a través de una mediación con el tseltal (Gómez, 2017). No obstante, es pertinente pasar ahora a la última sección de este artículo, en la que se revisarán las versiones de los pueblos involucrados acerca de su propia manera de ver y contar su historia.

\section{Mito, memoria e historia}

Desde su publicación, las afirmaciones de Mario Ruz (1983a) y Otto Schumann (1983b) acerca de que los chujes de San Mateo Ixtatán narran que antes los tojolabales vivían ahí, en San Mateo, han sido usadas de manera general por autores posteriores que se han interesado por las relaciones entre ambos pueblos mayas. En su texto, Schumann (1983b:164) asentó que «el centro histórico y ceremonial de mayor importancia para el grupo tojolabal (así como para el chuj) se encuentra en San Mateo Ixtatán, en territorio guatemalteco». En ese sentido, Ruz (1983a) explicó que los chujes:

Mantienen la tradición oral de haber desalojado de San Mateo Ixtatán a sus antiguos vecinos tojolabales durante una disputa por las minas de sal que existen en el pueblo; incluso señalan que éstos se localizaban en la cercana zona arqueológica conocida como el k'atepam (templo viejo o derruido), que se yergue enfrente del pueblo; separada de éste apenas por una barranca (Ruz, 1983a:46).

Empero, son los estudios de Carlos Navarrete (2008) y Ruth Piedrasanta (2009) los que ofrecen más información al respecto, a partir de su trabajo de campo en la región chuj. El primero de dichos autores recopiló alrededor de 1980, en San Mateo Ixtatán, un relato en el que se narra la 'historia mítica de la sal', que incluye un pasaje en el que se menciona a los habitantes del Catepán, un sitio arqueológico de la zona:

Los primeros que vivieron en el Catepán, se fueron al otro lado, a Comitán y Zapaluta. Vienen de romeristas cada año, antes que siembren, ellos vienen a recordar sus lugares y a llevarse su tecomate, su botella con agua de sal y su medicina, pus. Otros hermanos se separaron y quedaron en San Sebastián Coatán [...] Los zapalutas traen candelas y tambor, traen cohetes, cargan flores. Les damos posada en la iglesia y dejan manojos 
de candelas de seis quetzales. Traen mantel para el altar, adorno de papel, traen banderas, traen pito. Piden que los vientos de San Mateo lleven lluvia a sus tierras, pues (Navarrete, 2008:151).

Por su parte, Piedrasanta (2009) reunió numerosos relatos de la tradición oral chuj, entre los que también destacan aquellos sobre el origen de las minas de sal, tan importantes desde la época prehispánica. Relacionados con los relatos sobre la sal se encuentran los que hacen referencia al sitio arqueológico llamado Wajxaklajunhe, en lengua chuj, ubicado plenamente en el pueblo de San Mateo Ixtatán, como centro de origen y posterior dispersión de diferentes grupos humanos. La forma en que lo interpreta Piedrasanta (2009:65) es que, «después de situarse alrededor de la sal, los Chuj crecieron, se multiplicaron, se diferenciaron internamente y dieron inicio a las rivalidades o abiertas disputas por el control de las minas. Largos y detallados mitos nos hablan de ello». Inmediatamente, dicha autora anota que en una de las versiones que obtuvo, el narrador comienza por afirmar que toda la gente de San Mateo decía que el sitio de Wajxaklajunhe estaba formado por varios grupos de personas, que son los chujes de San Mateo propiamente, Ilamados Nawal en los relatos; los Chialon, identificados con los tojolabales por la antropóloga, aunque en otras versiones son relacionados con los «zapalutas», como aclara Piedrasanta (2009:65); y el grupo de los Yaxbatz, que corresponde con los chujes de San Sebastián Coatán. Un fragmento de la narración se muestra a continuación:

Cuando el agua de sal apareció, entonces es cuando ellos llegaban a traer su sal. [Entonces] la comunidad de este grupo Nawal y el grupo Chialon, estaban reunidos todavía con los de San Sebastián. Estaban unidos. Donde ellos comenzaron con problemas fue por la sal, porque no les alcanzaba [...] Ya después se apartaron, como a los Chialones no mucho les gustaban [los] problemas, se hicieron por un lado: entonces donde vieron el grupo Nawal que ellos se aislaron, entonces más se pegaron [a las minas]. Como les gustaba pelear esos del grupo Nawal, se separaron enemigos. Cuando ellos estaban en Wajxaklajunhe todos estaban unidos allí; pero por la sal 'tonces se hizo un lado el grupo Chialon

- Lo que vamos a hacer es que vamos a hacer otra habitación — dice que dijeron.

Fue cuando ellos llegaron allí a la iglesia... [allí] tenían su guarida. Como según los chialonistas es que ellos se querían defender [de los Nawal]... y tienen su guardia. Con eso están vigilando, controlando para ver si no llegaban... Entonces el grupo Nawal lo estuvieron rechazando y no sólo así de palabra, sino dicen que algunos eran coyotes, 
algunos eran leones. Esos perseguían a los chialones... Hasta que los sacaron y... se fueron. Porque ellos de noche iban a robar su sal. Ya cuando al grupo Nawal se daba cuenta, ya no estaba lleno el pozo. Entonces los persiguieron otra vez y se trasladaron por la tercera vez allá en Catepan [actual sitio arqueológico]. Ellos [el grupo Nawal] querían que ya no les tocara nada. Pero como ellos [los Chialon] ya se acostumbraron con su sal, [se] pasaron allá. Vivieron un buen tanto de días allí. Hicieron sus [habitaciones] en el Catepan que está abajo; pero siempre venían de noche a robar su sal. Entonces el grupo Nawal siempre estaban controlando quienes son. - Lo que vamos a hacer ahora es que vamos a controlar- dice que dijeron los del grupo Nawal. Ya los leones, los coyotes, algunas personas más también se iban allí. Entonces los agarraban dicen (Piedrasanta, 2009:65-66).

Posteriormente, de acuerdo con el relato, los del grupo Nawal siguieron persiguiendo a los Chialon a los lugares a los que se mudaban, cada vez más lejos de las minas de sal y del pueblo de San Mateo, hasta que los Chialon decidieron retirarse aún más lejos (Piedrasanta, 2009:67). Estas son algunas de las versiones que se han registrado acerca de las explicaciones sobre el origen multiétnico que tuvo lugar en San Mateo Ixtatán, de acuerdo con la tradición oral chuj. Existe otra, publicada en el libro Historia y memorias de la comunidad étnica chuj, editada por el Ministerio de Educación (2001), que forma parte de una recopilación de textos de tradición oral que narra la gente mayor chuj, en la que se apuntan otros datos de suma relevancia acerca del origen de los chujes y otros grupos.

De acuerdo con la historia contada por los ancianos y las ancianas, los primeros pobladores de la comunidad chuj fueron personas que integraban cuatro grupos distintos: los Tzapaluta, que actualmente habitan en la República de México; los de Ixtatán (tierra de sal o cerca de las salinas), que eran parte de los Tzapaluta. El tercer grupo habita actualmente Coatán (tierra de culebras); y el cuarto son los actuales habitantes de Santa Eulalia.

Los Tzapaluta tuvieron su pueblo en K'atepan, al norte de San Mateo; los de San Sebastián Coatán lo tuvieron al oriente, aproximadamente a dos kilómetros de San Mateo; los de Santa Eulalia lo tuvieron en el cantón Yunechonhab'; y los de San Mateo, en el lugar donde se encuentran las ruinas de Wajxaklajunh. Actualmente, los de San Mateo y San Sebastián son los únicos grupos hablantes de chuj que aún habitan en esta comunidad. No se conoce la historia de porqué se retiraron de aquí los de Santa Eulalia. Los Tzapaluta quisieron apoderarse de las minas de sal de San Mateo, pero los mateanos, a pesar de ser un grupo menor, lucharon y lograron que los Tzapaluta se retiraran a territorio mexicano [...] Actualmente, los Tzapaluta sólo llegan a hacer 
sus ceremonias, al final del año maya. Llegan a rendir homenaje a San Mateo con un conjunto musical y cohetes (Ministerio de Educación, 2001:18-19).

Según esta última, San Mateo Ixtatán es cuna de cuatro grupos humanos, al ubicar también ahí a los actuales habitantes de Santa Eulalia, centro q'anjob'al de primera importancia, además de los otros tres grupos mencionados en relatos anteriores. Llama la atención, como ya lo señalaba Piedrasanta (2009:65, nota 24), que al grupo que los mateanos corren de sus tierras por el conflicto con las salinas es identificado como los «zapalutas» o «tzapalutas», término que alude a los antiguos habitantes de Zapaluta, en Chiapas, población que actualmente se conoce como La Trinitaria. Queda entonces una duda razonable: ¿a quiénes se refiere exactamente la tradición chuj con el término de Chialon? Piedrasanta (2009:89) afirma que los Chialon efectivamente son el grupo que hoy conocemos como tojol-ab'al, pero, de cualquier forma, es muy interesante que en las distintas versiones de los relatos en cuestión sea intercambiado el término de Chialon por el de los zapalutas.

En este orden de ideas, conviene preguntarse por qué, si los tojolabales tienen un lugar trascendente en los relatos míticos de los chuj mateanos, no se conserva ningún testimonio al respecto en alguna de las comunidades tojolabales contemporáneas, a pesar de los esfuerzos, bastante notables, por registrar y reunir la mitología del pueblo (Gómez et al., 1999; La Chica, 2017). En repetidas ocasiones se ha mencionado que, como dice Ruz (1992a:18), «hoy el universo tojol-ab'al reivindica como primordialmente suyos los espacios geográficos que recuperó de las antiguas fincas; el marcador cronológico del origen es el periodo del 'baldío'», consideración a la que se adhiere Gómez (2014). Tal vez el único dato proveniente del ámbito tojol-ab'al que habla de una relación con los chujes es el que se desprende del ya casi desaparecido carnaval, mejor conocido en tojol-ab'al como ta'an k'oy. Sin entrar en detalle, para lo cual se remite al lector interesado a consultar la descripción que hace Ruz (1983b) sobre el carnaval, solo se mencionará que entre todos los personajes que aparecen en el ta'an k'oy, como «los viejos», "las mujeres», "las mudencas», los niños "cosito negro», entre otros, se encuentra un grupo denominado «los chujes». En el momento del carnaval, estos «chujes» son directamente los enemigos de los carnavaleros, con quienes se emprende un performance de guerra, que es el acto más destacado del carnaval. La siguiente es una breve descripción de Mario Ruz al respecto: 
El simulacro de batalla, cuyo resultado final es imprevisible aunque casi siempre obtienen la victoria los chujes, se realiza con olotes a manera de parque, y durante ella "los viejos" gritan despavoridos, y las "mudencas" corren de un lado a otro horrorizadas. Cuando los triunfadores son los guatemaltecos la tradición señala que todos los locales han de ser muertos y sus mujeres raptadas (Ruz, 1983b:213).

Llama la atención que la parte más significativa del carnaval tojol-ab'al sea la recreación de una pelea con sus vecinos chujes. Por tal motivo, Ruz no duda en interpretarlo como un resquicio de la antigua historia entre estos dos pueblos, comparando lo sucedido entre los tseltales de Bachajón en su carnaval, donde rememoran el sufrimiento acaecido por un ataque de los lacandones que sucedió a mediados del siglo XVI, referencia que el autor retoma para situar los acontecimientos del carnaval tojol-ab'al en la época prehispánica, debido a la inexistencia de documentos coloniales que lo refieran, y con ello apoyar la hipótesis de la etnogénesis tojol-ab'al en los Cuchumatanes (Ruz, 1983a:46).

En contraposición a la inexistencia de algún relato tojol-ab'al respecto a su origen en territorio chuj, sí se encuentran narraciones entre los habitantes de La Trinitaria, antes Zapaluta, acerca de eventos que relacionan a los diferentes pueblos que se han tratado en este texto. Aquí es necesario citar el relato que registró Enrico Straffi (2013) en su trabajo de campo, cuando acompañaba las romerías dirigidas a San Mateo Ixtatán, en el que logró observar las ceremonias que dirigen los principales de La Trinitaria en el sitio de Las Salinas, Ilevadas a cabo directamente en las importantes minas de sal de San Mateo:

Tuvieron [los de San Mateo Ixtatán] un problema [con] Margaritas y Comitán; [estos] se unieron para quitarle [el] poder de San Mateo, de las minas; porque [querían] traerse todas las minas de agua; [querían] que estuviera aquí en su lugar de ellos. Zapaluta no estaba metido en este problema; entonces esos años, en la antigüedad, cuatro rayos [de] Las Margaritas y Comitán se fueron [a San Mateo Ixtatán para] atraer todo lo que tenían allá, la energía o el poder que tenían ahí; [se fueron para] traérselo para acá, fueron a robar; pensaban ellos que no se iban a dar cuenta [los señores de San Mateo]; pero como siempre tenían esos poderes [la clarividencia y la capacidad de comunicarse de lejos] esos señores [los de San Mateo] se comunicaron con los de Trinitaria; entonces se van los Zapalutecos a apoyar a los de San Mateo y a rebatar [rescatar] las cosas que ellos [los de Comitán y Las Margaritas] se traían; se agarraron Margaritas y Comitán, y San Mateo y Trinitaria; se agarraron dos a dos. Que con truenos, con aire, un remolino de viento y mucha lluvia porque es, eran rayos; quedaron los 
Lagos de Montebello donde fue el pleito. Por eso quedó mucha agua en los Lagos de Montebello, en las lagunas; ahí se dieron, ahí rescataron [los de La Trinitaria y de San Mateo] lo que se traían robando [los de Comitán y Las Margaritas]; le quitaron las cosas, pues los poderes [robados]; [entonces] regresaron los de Zapaluta en San Mateo [y] entonces allá en San Mateo debió pasar allá eso de gratificación [d]el bastón; de que ayudaron [en el] combate (Straffi, 2013:261).

Aquí saltan a la vista las alianzas entre distintos pueblos, los poderes a los que recurrieron para enfrentarse entre ellos-identificados fundamentalmente con los de los rayos-, y las consecuencias del enfrentamiento, que, ni más ni menos, es el origen del sistema lagunar en el actual Montebello. Straffi (2015:476) concluiría que los recorridos rituales en los que se ven reunidos los mestizos de La Trinitaria y los tojolabales -hacia territorio chuj-, y que justamente les dan contexto a las narrativas mostradas arriba, fungen como un eslabón en el que mantienen «el particular lazo entre su identidad colectiva y el paisaje con los cuales se relacionan para motivaciones simbólicas o prácticas. Es este paisaje, simbólicamente significado, incorporado y transmitido oralmente por intermediarios seleccionados que permite a su identidad perpetuarse». Esta manera de concebir y vivir sus memorias y su historia confiere a los pueblos una riqueza particular que debe ser considerada en toda su complejidad, pues como dice Navarrete (1999:232), «se trata de comprender las tradiciones indígenas como documentos plenamente históricos con un fuerte componente mítico». En este sentido, considero fundamentales las posturas de autores como Ruz (1992a), Navarrete (1999), y Good (2015), entre otros, acerca de la importancia de visibilizar y estudiar las formas en que los pueblos «entienden su propia experiencia histórica y construyen la conciencia de su historicidad como pueblos; estas teorías locales de la historia son muy distintas de la visión de la historia occidental que define el campo en el medio académico» (Good, 2015:150). Mario Ruz (1992a) ya había advertido esto cuando se dedicó a estudiar la historia de los tojolabales narrada por ellos mismos, discutiendo la posición ortodoxa del quehacer historiográfico que rechaza otras posturas y planteamientos, de modo que:

La situación varía si partimos del hecho de estar frente a otro tipo de registro histórico e incluso, ¿por qué no?, frente a otra manera de concebir la Historia. El espacio social donde se expande la oralidad obviamente no puede ser contenido en los estrechos marcos de la escriturística; la aproximación etnológica al pasado de pueblos en buena medida a caballo entre nuevos y antiguos espacios, y que conjuntan tiempos cíclicos 
y lineales, difícilmente puede vaciarse en moldes preconcebidos desde la perspectiva historiográfica occidental (Ruz, 1992a:23).

La distancia entre ambas involucra fundamentalmente la imbricación de aspectos míticos con los históricos, por lo que Navarrete ha propuesto crear metodologías que permitan unir ambas posturas y visiones, ya que:

La relación entre la concepción histórica occidental y las concepciones históricas de otras sociedades, como las mesoamericanas, ya no debe tomar la forma de una confrontación entre dos formas opuestas de conocimiento en la que la primera busca reducir a las otras a su concepción de verdad o falsedad. Debe convertirse en un auténtico diálogo entre concepciones diferentes del tiempo, el devenir y los actores históricos, en suma un intercambio entre concepciones diferentes de lo que son el ser humano y la sociedad en el tiempo [...] Desde esta perspectiva, ya no se puede mantener la contraposición entre historia y mito (Navarrete, 1999:251-252).

\section{Consideraciones finales}

He intentado acercarme al pasado de los hablantes de tres lenguas mayas que las investigaciones lingüísticas modernas han relacionado estrechamente. El avance en el estudio, la descripción y la comparación de dichos idiomas ha sugerido situaciones de contacto lingüístico entre el tseltal y el chuj, que derivaron en el desarrollo de la lengua tojol-ab'al. Mi propósito en este trabajo fue volver a lo que sabemos respecto a la historia de estas tres comunidades de habla, para analizar los escenarios en los que las hipótesis lingüísticas pudieron haberse concretado. Traté, para ello, de congeniar dos visiones acerca del pasado de una región y sus pueblos, una sustraída del estudio de carácter histórico de los documentos coloniales disponibles, y la otra obtenida del recuerdo y la palabra de los descendientes de aquellas sociedades. En conjunto, ambas perspectivas demuestran que tseltales, chujes y tojolabales han compartido -y aún lo hacenno solo rasgos lingüísticos, sino también un territorio diverso y una historia fuertemente anclada a este último. En específico, si bien la información reunida aquí sigue siendo poca para brindar afirmaciones contundentes sobre el probable escenario en el que se dio el contacto entre tseltales y chujes -tomando en cuenta las posibilidades sugeridas por Law (2017a)-, la articulación de las maneras de concebir la historia de las relaciones entre estos pueblos permite inclinarse por 
aquel escenario caracterizado por la incursión de un grupo de habla tseltal en la región chuj. Sin duda, se tienen datos que deberán articularse de mejor manera con nuevas evidencias, como el dato de que buena parte de la toponimia de la región de Comitán y La Trinitaria proviene de la lengua chuj, además de que se sabe que, por lo menos a finales del siglo XVI, parte de las tierras de Zapaluta eran de los chujes. En ese sentido, recientemente se ha estudiado que habitantes de Comitán, en particular del barrio de Yalchivol, recuerdan que sus antepasados eran chujes venidos de Guatemala (Ruiz, 2017). El problema tiene varias piezas aún sin encontrar, pero una de las más relevantes sería conocer con mayor precisión cuál era el límite entre la región de habla tseltal y la de habla chuj en la época prehispánica.

Quedan por profundizar muchas cuestiones acerca de la confluencia de distintas lenguas mayas en la región en épocas tempranas de la Colonia. Una de ellas sería la presencia de palabras del chuj en el Vocabulario de lengua tzeldal según el orden de Copanabastla, de fray Domingo de Ara, escrito alrededor de 1560, en el que, por ejemplo, se emplearon los términos chulel y pixan para hacer referencia al sustantivo 'alma' (Ruz, 1985:218), el primero de origen tseltal y el segundo chuj. Hay que recordar que en el Libro de bautizos de CopanaguastlaComitán, del siglo XVI, se encuentran registradas tanto la lengua tseltal como la tojol-ab'al-icontiene también palabras en chuj?-. Un análisis mucho más completo sobre los nombres calendáricos registrados en dicho documento, haciendo una diferencia entre aquellos provenientes del tseltal, del tojol-ab'al, e incluso del chuj, sería fundamental para tener una noción más completa sobre la relación entre las lenguas y los pueblos. Sobre esto habría que señalar que el calendario registrado por Núñez de la Vega en el siglo XVIII no debe atribuirse-por lo menos no únicamente- al pueblo tseltal (Lenkersdorf, 1986), como lo hacen muchos autores, ya que varios nombres de los días no están en la lengua correspondiente, sino en idiomas de la rama q'anjob'alana, como ya lo habían sugerido Campbell y Gardner (1988). El análisis de los nombres calendáricos coloniales puede articularse con el estudio de las inscripciones jeroglíficas mayas de la región, tomando en cuenta los periodos Clásico y Posclásico; además de investigar las similitudes y diferencias entre los contextos arqueológicos que existen en la zona mencionada. Las aproximaciones etnológicas deberán también explorar las concepciones locales sobre el origen de sus propios pueblos, por ejemplo, entre los popti' o jacaltecos, quienes identifican a un personaje llamado B'alunh Q'ana como el progenitor de la etnia (Tejada y Nuttall, 2007), lo que ineludiblemente hace pen- 
sar en el antiguo nombre calendárico de Comitán. Tomando en cuenta estos y otros datos, habría que seguir tratando de tejer fino para reconstruir la historia de una región marcada por la confluencia de caminos entre pueblos y lenguas, veredas que aún se ocultan a nuestra visión.

\section{Fuentes de consulta}

Academia de las Lenguas Mayas de Guatemala (ALMG), 2003, Spaxti'al Slolenal. Vocabulario Chuj, $1^{\text {a}}$.ed., Guatemala, Academia de las Lenguas Mayas de Guatemala.

Álvarez, Carlos, 1993, «El patrón de asentamiento en Las Margaritas, Chiapas y su cronología tentativa», en Juan Pedro Laporte, H. Escobedo y S. Villagrán de Brady (eds.), VI Simposio de Investigaciones Arqueológicas en Guatemala, 1992, Guatemala, Museo Nacional de Arqueología y Etnología, pp. 462-473.

Álvarez, Carlos, Lynneth S. Lowe y Tomás Pérez, 1995, «Excavaciones recientes de un sitio Postclásico Tardío en Las Margaritas, Chiapas, México», en Juan Pedro Laporte y H. Escobedo (eds.), VIII Simposio de Investigaciones Arqueológicas en Guatemala, 1994, Guatemala, Museo Nacional de Arqueología y Etnología, pp.603-608.

Auer, Peter, 2014, «Language mixing and language fusion: when bilingual talk becomes monolingual», en Juliane Besters-Dilger, Cynthia Dermarkar, Stefan Pfänder y Achim Rabus (eds.), Congruence in Contact-induced Language Change. Language families, typological resemblance, and perceived similarity, Berlin, De Gruyter, pp. 294-336.

Calnek, Edward, 1970, «Los pueblos indígenas de las tierras altas», en Norman McQuown y Julian Pitt-Rivers (comps.), Ensayos de antropología en la zona central de Chiapas, Colección Antropología Social, 8, México, Instituto Nacional Indigenista, pp. 105-135.

Campbell, Lyle, 1987, «Tzeltal dialects: new and old», Anthropological Linguistics, 29(4), pp. 549-570.

Campbell, Lyle, 1988, The Lingüistics of Southeast Chiapas, Mexico, 50, Provo, New World Archaeological Foundation / Brigham Young University.

Campbell, Lyle, 2017, «Mayan history and comparison», en Judith Aissen, Nora England y Roberto Zavala (eds.), The Mayan Languages, Routledge Language Family Series, Londres, Nueva York, Routledge, pp. 43-61.

Campbell, Lyle y Brant Gardner, 1988, "Coxoh», en Lyle Campbell, The Linguistics of Southeast Chiapas, Mexico, 50, Provo, New World Archaeological Foundation / Brigham Young University, pp. 315-338.

Campbell, Lyle y Terrence Kaufman, 1985, «Mayan Linguistics: Where are we now?», Annual Review of Anthropology, 14, pp.187-198.

Castro, Verónica, 2005, Breve historia de una comunidad tojolabal. Territorio y memoria colectiva en la región de Las Cañadas, Chiapas, tesis de licenciatura inédita, México, Universidad Nacional Autónoma de México. 
Croft, William, 2003, «Mixed languages and acts of identity: an evolutionary approach», en Yaron Matras y Peter Bakker (eds.), The mixed language debate. Theoretical and empirical advances, Berlín, Mouton de Gruyter, pp. 41-72.

Cruz, Jorge y Gabriela Robledo, 2003, «Frontera sur: contexto histórico y regional de Comitán y Las Margaritas, Chiapas», Relaciones. Estudios de historia y sociedad, XXIV (93), pp. 135-151.

Dakin, Karen, 1988, "Las lenguas kanjobalanas, polémicas clasificatorias», en Aurora M. Ocampo (ed.), Studia Humanitas: Homenaje a Rubén Bonifaz Nuño, México, UNAM, pp. 111-133.

De Vos, Jan, 1994, Vivir en frontera. La experiencia de los indios de Chiapas, México, Centro de Investigaciones y Estudios Superiores en Antropología Social / INI.

De Vos, Jan, 1988, La paz de Dios y del Rey. La conquista de la Selva Lacandona (15251821) $2^{a}$. ed., México, Secretaría de Educación y Cultura de Chiapas /Fondo de Cultura Económica.

Gómez, Antonio, 2014, La asamblea ejidal, arena de poder y negociación, México, Universidad Autónoma de Chiapas.

Gómez, Antonio y Mario Ruz, 1992, Memoria baldía. Los tojolabales y las fincas: testimonios, México, UNAM/ UNACH.

Gómez, Antonio, María Palazón y Mario Ruz (eds.), 1999, Palabras de nuestro corazón. Mitos, fábulas y cuentos maravillosos de la narrativa tojolabal, México, UNAM/UNACH.

Gómez, José, 2017, Estructuras morfosintácticas del tojol-ab'al en perspectiva comparativa: el caso de una lengua maya mixta, tesis de doctorado inédita, México, CIESAS.

Good, Catharine, 2015, «Mesoamérica vista desde la etnografía. Reflexiones críticas y propuestas», en Andrés Medina y Mechthild Rutsch (coords.), Senderos de la antropología. Discusiones mesoamericanistas y reflexiones históricas, Colección Etnología y Antropología Social, Serie Enlace, México, Instituto Nacional de Antropología e Historia/Instituto de Investigaciones Antropológicas-UNAM, pp. 147-164.

Halpern, Abraham, 1942, "A theory of Maya tš-sounds», Notes on Middle American Archaeology and Ethnology, 1, pp. 51-62.

Hopkins, Nicholas, 2012, A dictionary of the chuj (mayan) language. As spoken in San Mateo Ixtatán, Huehuetenango, Guatemala, Florida, Jaguar Tours.

Houston, Stephen, John Robertson y David Stuart, 2000, «The Language of Classic Maya Inscriptions», Current Anthropology, 41(3), pp. 321-356.

Kaufman, Terrence, 1964, «Materiales lingüísticos para el estudio de las relaciones internas y externas de la familia de idiomas mayanos», en Evon Z. Vogt y Alberto Ruz (eds.), Desarrollo cultural de los mayas, México, UNAM, pp. 81-136.

Kaufman, Terrence, 1976, "Archaeological and linguistic correlations in Mayaland and associated areas of Mesoamerica», World Archaeology, 8(1), pp. 101-118.

Kaufman, Terrence, 2017, "Aspects of the lexicon of proto-mayan and its earliest descendants», en Judith Aissen, Nora England y Roberto Zavala (eds.), The Mayan Languages, Routledge Language Family Series, Londres y Nueva York, Routledge, pp. 62-111.

Kroeber, Alfred, 1939, Cultural and Natural Areas of Native North America, vol. 38, Berkeley, University of California Press. 
La Chica, María-Cruz, 2017, Narrativa de tradición oral maya tojolabal, Madrid, Instituto Universitario de Investigación en Estudios Latinoamericanos, Universidad de Alcalá / Marcial Pons.

Law, Danny, 2009, «Pronominal borrowing among the Maya», Diachronica, 26(2), pp. 214-252.

Law, Danny, 2011, Linguistic inheritance, social difference, and the last two thousands years of contact among lowland mayan languages, tesis de doctorado inédita, Austin, The University of Texas at Austin.

Law, Danny, 2017a, «Language mixing and genetic similarity. The case of Tojol-ab'al», Diachronica, 34(1), pp. 40-78.

Law, Danny, 2017b, «Language contacts with(in) mayan», en Judith Aissen, Nora England y Roberto Zavala (eds.), The Mayan Languages, Routledge Language Family Series, Londres, Nueva York, Routledge, pp. 112-127.

Lenkersdorf, Carlos, 2010, B'omak'umal kastiya-tojol'ab'al 2. Diccionario español-tojolabal, idioma mayense de Chiapas, 3ª. ed., México, Plaza y Valdés.

Lenkersdorf, Gudrun, 1986, "Contribuciones a la historia colonial de los tojolabales», en Mario Ruz (ed.), Los legítimos hombres. Aproximación antropológica al grupo tojolabal, vol. IV, México, Centro de Estudios Mayas-Instituto de Investigaciones Filológicas-UNAM, pp. 13-102.

Lenkersdorf, Gudrun, 1993, Génesis histórica de Chiapas, 1522-1532: el conflicto entre Portocarrero y Mazariegos, México, IIF-UNAM.

Lenkersdorf, Gudrun, 1995, «Atahuistlan en los documentos coloniales. Un pueblo tojolabal de frontera», en Memorias del Tercer Congreso Internacional de Mayistas, t. 2, México, UNAM.

Lenkersdorf, Gudrun, 2001, Repúblicas de indios. Pueblos mayas en Chiapas, siglo XVI, México, IIF-UNAM.

Lipski, John, 2009, «'Fluent disfluency' as congruent lexicalization: a special case of radical code-mixing», Journal of Language Contact, VARIA series (2), pp. 1-39.

Lowe, Lynneth y Carlos Álvarez, 2007, «Recent explorations at the Postclassic Site of Los Cimientos de Las Margaritas, Chiapas», en Lynneth S. Lowe y Mary E. Pye (eds.), Archaeology, Art, and Ethnogenesis in Mesoamerican Prehistory: Papers in honor of Gareth W. Lowe, 68, Provo, New World Archaeological Foundation / Brigham Young University, pp. 321-335.

Lowe, Lynneth, Carlos Álvarez y Mauricio Ruiz, 2011, «lconografía de los sellos posclásicos del sitio Cimientos de Las Margaritas, Chiapas», en María del Carmen Valverde Valdés y Victoria Solanilla Demestre (coords.), Las imágenes precolombinas. Reflejo de saberes, México, UNAM, pp. 117-131.

Matras, Yaron, 2009, Language contact, Nueva York, Cambridge University Press.

Matras, Yaron y Peter Bakker, 2003, «The study of mixed languages», en Yaron Matras y Peter Bakker (eds.), The mixed language debate. Theoretical and empirical advances, Berlin, Nueva York, Mouton de Gruyter, pp. 1-20.

McQuown, Norman A., 1956, "The Classification of the Mayan Languages», International Journal of American Linguistics, 22(3), pp. 191-195. 
Ministerio de Educación, 2001, Historia y memorias de la comunidad étnica chuj, volumen II, versión escolar, Eleuterio Cahuec del Valle (ed.), Guatemala, Universidad Rafael Landivar / UNICEF / FODIGUA.

Muysken, Pieter, 2000, Bilingual speech. A tipology of code-mixing, Cambridge, Cambridge University Press.

Navarrete, Carlos, 2008, «El origen de la sal en la tradición oral de San Mateo Ixtatán y la peregrinación de los zapalutas», separata en Anales de la Academia de Geografía e Historia de Guatemala, t. LXXXIII, pp. 147-172.

Navarrete, Federico, 1999, "Las fuentes indígenas más allá de la dicotomía entre historia y mito», Estudios de Cultura Náhuatl, 30, pp. 231-256.

Palka, Joel y Josuhé Lozada, 2018, «El periodo Posclásico en Chiapas y sus sitios arqueológicos más representativos», en A. Kolpakova, A. Tovalín, A. Sheseña, J. Moscoso, J. Palka y J. Lozada (autores), Historia de Chiapas I. Época prehispánica, México, Editorial Entretejas, pp. 89-120.

Pérez, Cristóbal, 2019, La territorialidad como conocimiento cultural: indicios de reterritorialización del pueblo maya chuj en México, tesis de maestría inédita, Tuxtla Gutiérrez, Universidad Autónoma de Chiapas.

Piedrasanta, Ruth, 2009, Los Chuj: unidad y rupturas en su espacio, Guatemala, Armar Editores.

Polian, Gilles, 2017, Diccionario Multidialectal del tseltal (versión preliminar), en <https:// es.scribd.com/document/363089183/Diccionario-multidialectal-del-tseltal-pdf>.

Robertson, John, 1977, «A proposed revision in Mayan Subgrouping», International Journal of American Linguistics, 43(2), pp. 105-120.

Robertson, John, 1992, The History of Tense/Aspect/Mood/Voice in the Mayan Verbal Complex, Austin, University of Austin Press.

Ruiz, Alexander, 2017, Recuerdo y olvido en la multiculturalidad de pueblos originarios de Comitán de Domínguez, Chiapas, México, tesis de doctorado inédita, San Cristóbal de Las Casas, El Colegio de la Frontera Sur.

Ruz, Mario H., 1983a, «En torno a los orígenes», en Mario Humberto Ruz (ed.), Los legítimos hombres. Aproximación antropológica al grupo tojolabal, vol. I, México, Centro de Estudios Mayas-IIF-UNAM, pp. 23-60.

Ruz, Mario H., 1983b, Los legítimos hombres. Aproximación antropológica al grupo tojolabal, vol. II, México, Centro de Estudios Mayas-IIF-UNAM.

Ruz, Mario H., 1985, Copanaguastla en un espejo. Un pueblo tzeltal en el Virreinato, San Cristóbal de Las Casas, Centro de Estudios Indígenas, UNACH.

Ruz, Mario H., 1986, «Presentación», en Mario Humberto Ruz (ed.), Los legítimos hombres. Aproximación antropológica al grupo tojolabal, vol. IV, México, Centro de Estudios Mayas-IIF-UNAM, pp. 9-11.

Ruz, Mario, 1992a, «Introducción», en Antonio Gómez Hernández y Mario H. Ruz (eds.), Memoria baldía. Los tojolabales y las fincas. Testimonios, México, UNAM /UNACH, pp. 17-25.

Ruz, Mario, 1992b, Savia india, floración ladina. Apuntes para una historia de las fincas comitecas (siglos XVIII y XIX), México, Consejo Nacional para la Cultura y las Artes. 
Ruz, Mario, 1999, «Un corazón vivo, una palabra actual», en Antonio Gómez Hernández, María Rosa Palazón y Mario Humberto Ruz (eds.), Ja slo'il ja kaltziltikoni'. Palabras de nuestro corazón. Mitos, fábulas y cuentos maravillosos de la narrativa tojolabal, México, UNAM / UNACH, pp. 27-69.

Schumann, Otto, 1970, «La posición del tojolabal en la familia maya», Boletín informativo. Escritura Maya, 4(2), pp. 4-9.

Schumann, Otto, 1983a, "Algunos aspectos de la relación chuj-tojolabal», en Lorenzo Ochoa y Thomas A. Lee. Jr. (eds.), Antropología e historia de los Mixe-Zoques y Mayas. Homenaje a Frans Blom, México, UNAM / Brigham Young University, pp. 355-363.

Schumann, Otto, 1983b, «La relación lingüística chuj-tojolabal», en Mario H. Ruz (ed.), Los legítimos hombres. Aproximación antropológica al grupo tojolabal, vol. I, México, Centro de Estudios Mayas-IIF-UNAM, pp. 129-169.

Stoll, Otto, 1884, Zur Ethnographie der Republik Guatemala, Zürich, Druck und Verlag von Orell Füssli.

Straffi, Enrico, 2013, «Interpretaciones mayas de los sitios arqueológicos: un análisis», en Heriberto Cairo, Almudena Cabezas, Tomás Mallo, Esther del Campo y José Carpio (eds.), XV Encuentro de Latinoamericanistas Españoles, Madrid, Trama Editorial/ CEEIB, pp. 252-271.

Straffi, Enrico, 2015, Ofrendas para la lluvia: transformaciones en los recorridos rituales en el sur de Chiapas, tesis de doctorado inédita, Madrid, Universidad Complutense de Madrid.

Swadesh, Mauricio, 1960, «Interrelaciones de las lenguas mayenses», Anales del Instituto Nacional de Antropología e Historia, XIII, pp. 231-267.

Tejada, Mario y Deidre Nuttall, 2007, «Tradiciones orales de Huehuetenango. Primera parte», Tradiciones de Guatemala, 68, pp. 155-246.

Thomason, Sarah, 2003, «Social factors and linguistic processes in the emergence of stable mixed languages», en Yaron Matras y Peter Bakker (eds.), The mixed language debate. Theoretical and empirical advances, Berlín, Mouton de Gruyter, pp. 21-39.

Valiñas, Leopoldo, 2010, «Historia lingüística: Migraciones y asentamientos. Relaciones entre pueblos y lenguas», en Rebeca Barriga Villanueva y Pedro Martín Butragueño (dirs.), Historia sociolingüística de México, 1. México prehispánico y colonial, México, Centro de Estudios Lingüísticos y Literarios-El Colegio de México, pp. 97-160.

Viqueira, Juan Pedro, 1997, Cronotopología de una región rebelde. La construcción histórica de los espacios sociales en la Alcaldía Mayor de Chiapas (1520-1720), tesis de doctorado, París, Escuela de Altos Estudios en Ciencias Sociales.

\section{Cómo citar este artículo:}

Guerrero Martínez, Fernando, 2020, «Reflexiones en torno a la historia de las relaciones entre tojolabales, tseltales y chujes», Revista Pueblos y fronteras digital, volumen 15, e-439. https://doi.org/10.22201/cimsur.18704115e.2020.v15.439 